\title{
Constant Intravenous Infusion of Chlorpromazine for Both Sedation and After-Load Reduction in Postcardiotomy Patients under Intraaortic Balloon Pumping
}

\author{
Hisanori Mayumi, M.D. and Kouichi Tonunaga, M.D.
}

SUMMARY

Continuous intravenous infusion of chlorpromazine (CPZ) was used for both sedation and after-load reduction in 13 Japanese patients (Group 1) supported by an intraaortic balloon pump (IABP) after open-heart surgery. CPZ was initiated at a dose of $0.05 \mathrm{mg} / \mathrm{kg} / \mathrm{hr}$ and was maintained in an approximate dose range of $0.1-0.3 \mathrm{mg} / \mathrm{kg} / \mathrm{hr}$ depending on individual patient needs. The drug was administered until the IABP was removed and the blood gases were normalized. During this period, the patients slept well and the trigger lines for the IABP were sufficiently secured. In order to evaluate the hemodynamic changes in these patients, the 10 patients who were supported by the IABP and given continuous intravenous sodium thiamylal (ST) for sedation in an approximate dose range of $1-2 \mathrm{mg} / \mathrm{kg} / \mathrm{hr}$ (Group 2) were employed as controls. After administration of CPZ, the systemic vascular resistance, central venous pressure, and left atrial pressure decreased, while the cardiac output increased. The predicted untoward effects of CPZ, such as tachycardia and hypotension, were minimal. In the ST group, by contrast, the cardiac output decreased somewhat in association with the increase in systemic vascular resistance. From these results, we conclude that constant intravenous CPZ is beneficial for postcardiotomy patients who have severe low cardiac output syndrome and are supported with IABP, by both successfully sedating the patients and reducing ventricular afterload.

\section{Key Words:}

Open heart surgery Vasodilator Major tranquilizer Postcardiotomy delirium Postoperative psychosis Low cardiac output syndrome Denopamine

From the Division of Cardiovascular Surgery, Research Institute of Angiocardiology, Faculty of Medicine, Kyushu University, Fukuoka, Japan.

Correspondence to: Hisanori Mayumi, M.D., Department of Cardiovascular Surgery, Matsuyama Red Cross Hospital, 1 Bunkyocho, Matsuyama City, Ehime 790, Japan.

Received for publication April 15, 1991.

Accepted July 15, 1991. 
$\mathrm{N}$ intraaortic balloon pump (IABP) is one of the most beneficial devices ${ }^{1,2)}$ for the treatment of patients with severe low cardiac output syndrome (LOS) after cardiac surgery. Since this device requires continuous monitoring of electrocardiograms (ECG) or arterial pressures as a trigger to determine the optimal timing of the inflation and deflation of the balloon, ${ }^{11}$ it is extremely important to secure these monitoring lines from any movement that might possibly cause electrical noise. Patients with severe LOS, however, tend to experience postcardiotomy delirium ${ }^{3)-5}$ and to remove themselves from their life-lines, including the IABP catheter, arterial pressure line, central venous pressure (infusion) line, left atrial pressure line, Swan-Ganz catheter, intratracheal respiratory tube, and intrapericardial drains, when adequate sedatives are not given.

For sedating such critically ill patients, various drugs may be used, including barbiturates, opioids, major and minor tranquilizers, and muscle relaxants. ${ }^{6}$ ) Before 1988, we had extensively used a bolus IV injection of diazepam, buprenorphine, pentazocine, haloperidol, morphine, fentanyl, and/or pethidine alone or combined with pancuronium bromide, in order to sedate these patients. The bolus injections, however, often caused harmful hemodynamic changes in patients with severe LOS. Moreover, the effectiveness of the drugs is usually of short duration.

Since 1988, we have been using a continuous intravenous infusion of chlorpromazine (CPZ) for patients with IABP. This drug was chosen because it is a well-known major tranquilizer and its $\alpha$-blocking action appears to be appropriate for adequately reducing the after-load of the damaged heart. ${ }^{7)-9}$ ) On the other hand, continuous intravenous infusion with sodium thiamylal (ST) has also been used at our institution, especially for patients with air embolism or ischemic brain damage suffered during cardiopulmonary bypass. ${ }^{10-12)}$ This method, however, has also been extended since 1987 to patients with IABP in order to sedate them. Although both drugs were effective in sedating the patients, CPZ was found to be even more effective than ST in improving the hemodynamics of the patients in the present study.

\section{Patients AND Methods}

Patients: Twenty-three Japanese patients who underwent open heart surgery from June 1988 to June 1990 at Kyushu University Hospital and had suffered scvcre LOS after weaning from cardiopulmonary bypass were included in this study. All of the patients were treated with an IABP (K-2000, Kontron, Everett, Mass.) either during the operation or after ad- 
mission to the intensive care unit (ICU). We used an IABP when weaning from cardiopulmonary bypass was difficult because of the following conditions: systolic aortic pressure $<80 \mathrm{mmHg}$, left atrial pressure $>15 \mathrm{mmHg}$, cardiac index $<2.01 / \mathrm{min} / \mathrm{m}^{2}$, and dopamine plus dobutamine $>10 \mu \mathrm{g} / \mathrm{kg} /$ min. Neither norepinephrine nor epinephrine was used until IABP was found to be insufficient to support the discased heart. Out of 23 patients, 13 were given continuous CPZ (Contomin $5 \mathrm{mg} / \mathrm{ml}$; Yoshitomi, Osaka, Japan) in a dose range of $0.05-0.29 \mathrm{mg} / \mathrm{kg} / \mathrm{hr}$ (Group 1). The drug was started with a small dose (usually, $0.05 \mathrm{mg} / \mathrm{kg} / \mathrm{hr}$ ) and then gradually increased up to the dose level at which the patients were able to sleep well but awoke with a cough reflex at the time of suctioning of sputa and tracheobronchial toilet. When $\mathrm{CPZ}$ was started, the continuous intravenous infusion of sodium nitroprusside (SNP; $0.48 \pm 0.23 \mu \mathrm{g} / \mathrm{kg} / \mathrm{min}$ ) was discontinued gradually over several hours. For the control group (Group 2), 10 patients were given continuous ST (Isozol; Yoshitomi) in a dose range of $0.55-2.15 \mathrm{mg} / \mathrm{kg} / \mathrm{hr}$. The drug $(25 \mathrm{mg} / \mathrm{ml})$ was usually started at a rate of $1 \mathrm{mg} / \mathrm{kg} / \mathrm{hr}$ and then was gradually increased as well. The drugs were infused by a microinfusion pump (Infusion pump 235; Atom, Tokyo).

IABP was weaned when the cardiac index increased to $>2.5 \mathrm{l} / \mathrm{min} / \mathrm{m}^{2}$ under $<5 \mu \mathrm{g} / \mathrm{kg} / \mathrm{min}$ of dopamine plus dobutamine.

In both of the groups, IABP was usually weaned first, followed by weaning from the respirator. The sedatives were discontinued before weaning from the respirator was initiated.

Measurements: In all of the patients, a Swan-Ganz catheter was inserted either before or during the operation. Cardiac output (the mean of 3 trials) was examined by the thermodilution technique right before, and approximately 5,12, and 24 hours after starting the drugs. Thereafter, cardiac output was measured usually twice a day. At the time of cardiac output measurement, the heart rate, mean aortic pressure, central venous pressure, left atrial pressure (pulmonary capillary wedge pressure), and mean pulmonary arterial pressure were all recorded. A hemodynamic calculation was performed using the HP component monitoring system (HewlettPackard, Waltham, Mass.).

Statistics: Student's t-test was performed to compare parametric data that were expressed as the mean $\pm \mathrm{SD}$ in 2 groups. The chi-square test with Yates' correction was also used to compare the incidences in 2 groups. To compare the hemodynamic data, a two-way analysis of variance (ANOVA) was performed first. ${ }^{13)}$ Only when the variance was significant was the modified Student's t-test performed. ${ }^{13,14)}$ For multiple comparisons, the Bonferroni correction was used. ${ }^{13\}, 14)} \mathrm{P}$ value was calculated by means 
of a personal computer (PB-700, Casio, Tokyo). A p value of $<0.05$ was taken to be significant.

\section{Results}

Profile of the patients: The details of the patients in Group 1 (CPZ; $\mathrm{n}=13)$ and Group $2(\mathrm{ST} ; \mathrm{n}=10)$ are presented in Table I. As predicted from the use of IABP, the patients were exposed to a prolonged period of cardiac arrest and cardiopulmonary bypass in both groups. The dose of dopamine plus dobutamine was $>10 \mu \mathrm{g} / \mathrm{kg} / \mathrm{min}$ in most of the patients in both groups at the beginning of the study. The vasodilators used right before this study were nitroglycerin (NTG) and sodium nitroprusside (SNP). In Group 1, SNP was replaced with CPZ, and was discontinued within several hours, whereas it was continued as previously given in Group 2. The differences in these data in the 2 groups were statistically insignificant. The New York Heart Association functional class, however, was more severe in Group 1 than that in Group 2 (Table I).

General outcome of the treatment: In Group 1, IABP was used for $6.1 \pm 3.4$ (mean $\pm \mathrm{SD}$ ) days (Table II). CPZ in a maximal dose of 0.16

Table I. Profiles of the Patients

\begin{tabular}{|c|c|c|c|}
\hline & \multirow{2}{*}{$\frac{\text { Group } 1}{\text { CPZ }}$} & Group 2 & \multirow{2}{*}{ P-value } \\
\hline & & ST & \\
\hline No. of patients & 13 & 10 & - \\
\hline Male/Female & $7 / 6$ & $2 / 8$ & NS \\
\hline Age (years) & $\begin{array}{r}54.6 \pm 14.3 \\
(\text { range } 19-70)\end{array}$ & $\begin{array}{r}57.6 \pm 10.4 \\
\text { (range 38-67) }\end{array}$ & NS \\
\hline \multicolumn{4}{|l|}{ Diagnosis } \\
\hline VHD & 6 & 5 & \\
\hline IHD & 4 & 3 & \\
\hline $\mathrm{VHD}+\mathrm{IHD}$ & 3 & 0 & \\
\hline CHD & 0 & 1 & \\
\hline ANEURYSM & 0 & 1 & \\
\hline NYHA & $3.5 \pm 0.5$ & $2.7 \pm 1.0$ & 0.020 \\
\hline $\mathrm{AXT}(\min )$ & $165.9 \pm 76.9$ & $149.6 \pm 101.8$ & NS \\
\hline $\mathrm{CPBT}(\mathrm{min})$ & $254.2 \pm 112.3$ & $275.9 \pm 205.2$ & NS \\
\hline $\mathrm{DOP}+\mathrm{DOB}(\mu \mathrm{g} / \mathrm{kg} / \mathrm{min})$ & $11.5 \pm 4.6$ & $12.1 \pm 6.6$ & NS \\
\hline $\mathrm{NTG}(\mu \mathrm{g} / \mathrm{kg} / \mathrm{min})$ & $0.65 \pm \quad 0.28$ & $0.63 \pm 0.30$ & NS \\
\hline $\mathrm{SNP}(\mu \mathrm{g} / \mathrm{kg} / \mathrm{min})$ & $0.48 \pm 0.23$ & $0.47 \pm 0.25$ & NS \\
\hline
\end{tabular}

$\mathrm{CPZ}=$ chlorpromazine; $\mathrm{ST}=$ sodium thiamylal; $\mathrm{NS}=$ not significant $\mathrm{VHD}=$ valvular heart disease; $\mathrm{IHD}=$ ischemic heart disease; $\mathrm{CHD}=$ congenital heart disease; NYHA $=$ New York Heart Association; $\mathrm{AXT}=$ aortic cross clamping time; $\mathrm{CPBT}=$ cardiopulmonary bypass time; $\mathrm{DOP}=$ dopamine; $\mathrm{DOB}=$ dobutamine $\mathrm{NTG}=$ nitroglycerin $; \mathrm{SNP}=$ sodium nitroprusside. 
Table II. General Outcome of the Treatment

\begin{tabular}{lcccc}
\hline & Group 1 & Group 2 & \multirow{2}{*}{ P-value } \\
\cline { 2 - 3 } & CPZ & ST & \\
\hline No. of patients & 13 & & 10 & - \\
Use of IABP (days) & $6.1 \pm 3.4$ & & $7.3 \pm 3.7$ & NS \\
$\quad$ (range) & $(3-15)$ & & $(3-14)$ & \\
Use of the drug (days) & $9.8 \pm 10.6$ & & $5.3 \pm 4.0$ & NS \\
$\quad$ (range) & $(3-32)$ & & $(2-14)$ & \\
Maximal dose (mg/kg/hr) & $0.16 \pm 0.08$ & & $1.31 \pm 0.54$ & - \\
$\quad$ (range) & $(0.05-0.29)$ & & $(0.55-2.15)$ & \\
Use of respirator (days) & $16.1 \pm 13.9$ & & $9.9 \pm 5.6$ & NS \\
$\quad$ (range) & $(3-40)$ & & $(4-17)$ & \\
ICU stay (days) & $17.6 \pm 14.6$ & & $10.7 \pm 5.1$ & NS \\
$\quad$ (range) & $(4-43)$ & & $(5-18)$ & \\
Hospital death & $1 / 13$ & & $2 / 10$ & NS \\
\hline
\end{tabular}

$\mathrm{CPZ}=$ chlorpromazine; $\mathrm{ST}=$ sodium thiamylal; $\mathrm{NS}=$ not significant $; \mathrm{IABP}=$ intraaortic balloon pump; ICU = intensive care unit.

$\pm 0.08 \mathrm{mg} / \mathrm{kg} / \mathrm{hr}$ was given for $9.8 \pm 10.6$ days. A respirator was necessary for $16.1 \pm 13.9$ days. The patients were discharged from ICU at $17.6 \pm 14.6$ days after the operation. Hospital death was observed in 1 patient out of the 13. The patient, with aortic and mitral regurgitation due to giant cell aortitis, had undergone a double valve replacement with Hancock bioprotheses and tricuspid annuloplasty 8 years earlier. The patient showed severe low cardiac output syndrome and acute renal failure because of aortic and mitral periprosthetic leakage (at first these were diagnosed as primary tissue failure of the bioprostheses) due to acute exacerbation of giant cell aortitis. After a double valve replacement with St. Jude Medical valves, the patient died of multiple organ failure 21 days after operation.

In Group 2, by contrast, IABP was required for $7.3 \pm 3.7$ days. ST in a maximal dose of $1.31 \pm 0.54 \mathrm{mg} / \mathrm{kg} / \mathrm{hr}$ was given for $5.3 \pm 4.0$ days. A respirator was required for $9.9 \pm 5.6$ days. The postoperative stay in the ICU was 10.7 \pm 5.1 days. Two patients died in this Group. Both of the patients had undergone a double valve replacement with bioprostheses and tricuspid annuloplasty previously, and had a double valve replacement with St. Jude Medical valves in an elective or emergent fashion, respectively. Preoperative complication of liver cirrhosis or acute renal failure triggered the occurrence of multiple organ failure in each of these cases. The patients died 18 and 10 days after operation, respectively.

Despite the preoperatively more severe conditions in Group 1, the use of IABP appeared to be shorter in Group 1 than that in Group 2, although this difference did not attain statistical significance (Table II). On the 
contrary, longer sedation, respirator and ICU stay periods were required for Group 1 than for those in Group 2. This discrepancy may be ascribed to pulmonary dysfunction and acute renal failure which were experienced for prolonged periods in 2 of the Group 1 patients.

Hemodynamic changes in CPZ- or ST-treated patients: The hemodynamic changes after CPZ or ST treatment are presented at 3 different time points, i.e., right before, 3-6 hours after, and 18-30 hours after each drug was initiated (Figs. 1-3). The heart rate and mean aortic pressure did not significantly change in either of the groups (Fig. 1). In the CPZ group (Group 1), the heart rate appeared to increase while the mean
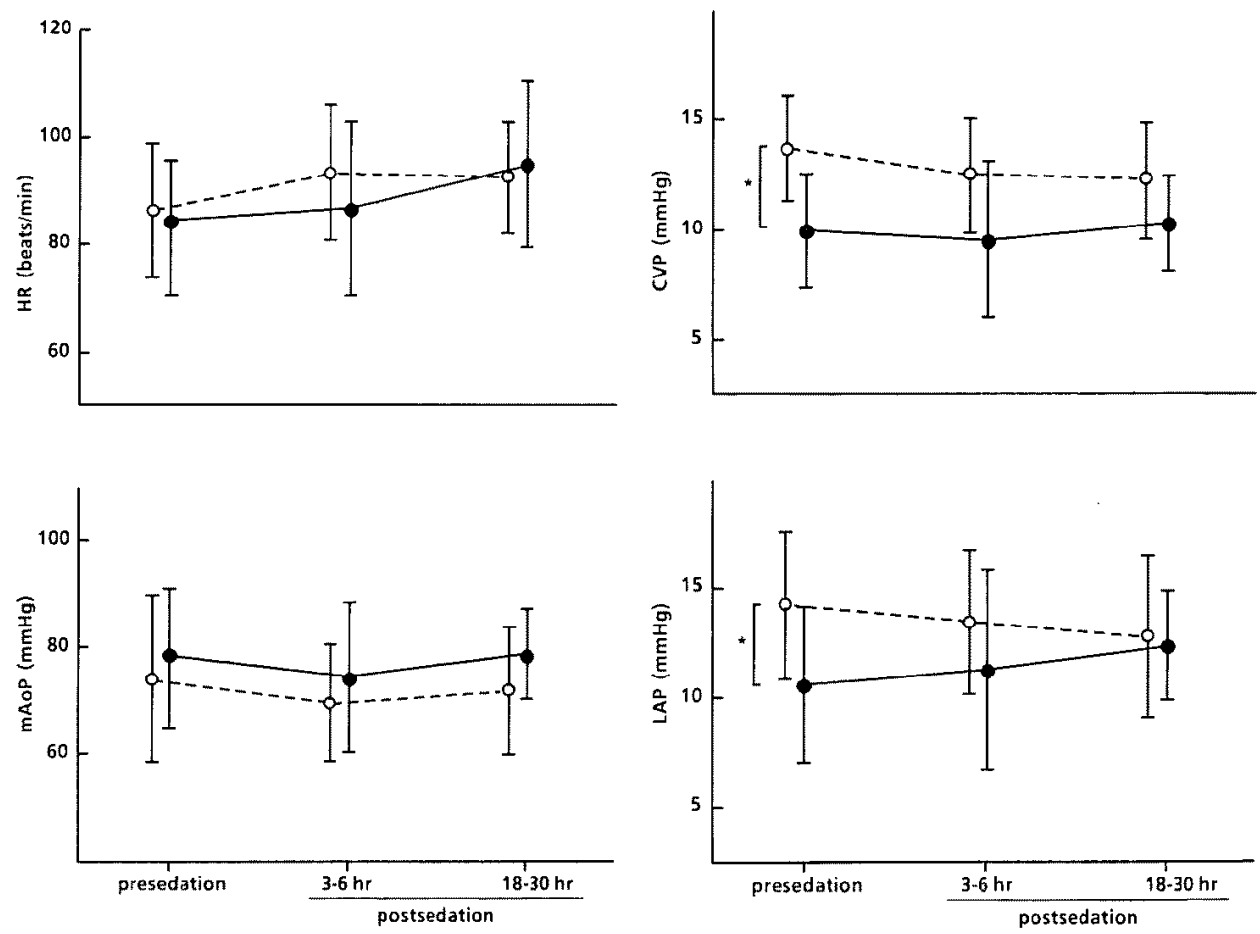

Fig. 1. Hemodynamic changes after chlorpromazine or sodium thiamylal administration (1). $\mathrm{HR}=$ heart rate; $\mathrm{mAoP}=$ mean aortic pressure; CPZ (O, $\mathrm{n}=13)$; ST $(O, \mathrm{n}=10)$. Two-way ANOVA for upper panel; $\mathrm{p}=0.551$ (drugs), 0.125 (time points), and 0.580 (interaction). Two-way ANOVA for lower panel; $\mathrm{p}=0.083$ (drugs), 0.53 (time points), and 0.933 (interaction).

Fig. 2. Hemodynamic changes after chlorpromazine or sodium thiamylal administration (2). $\quad C V P=$ central venous pressure; $L A P=$ left atrial pressure; $\operatorname{CPZ}(O, \mathrm{n}=13)$; $\mathrm{ST}(\mathbf{O}, \mathrm{n}=$ 10). Two-way ANOVA for upper panel; $p=$ 0.00003 (drugs), 0.550 (time points), and 0.556 (interaction). $\left({ }^{*}\right), \mathrm{p}=0.0014$ by the modified $t$-test. Two-way ANOVA for lower panel; $\mathrm{p}=$ 0.016 (drugs), 0.990 (time points), and 0.321 (interaction). (*), $\mathrm{p}=0.016$ by the modified t-test. 

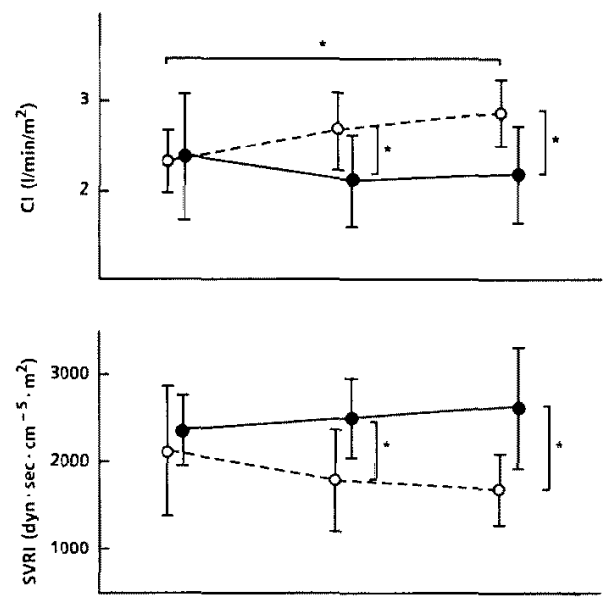

Fig. 3. Hemodynamic changes after chlorpromazine or sodium thiamylal administration (3). $\mathrm{GI}=$ cardiac index; SVRI = systemic vascular resistance index; I.CWI $=$ left cardiac work index; $\mathrm{CPZ}(\mathrm{O}, \mathrm{n}=13)$; ST $(\boldsymbol{O}, \mathrm{n}=10)$.

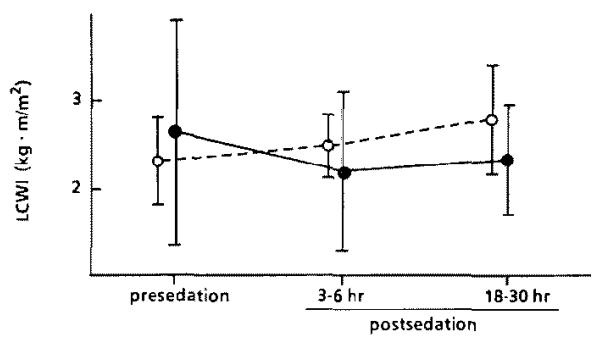
Two-way ANOVA for upper panel; $p=0.002$ (drugs), 0.047 (time points), and 0.030 (interaction). (*), p $<0.05$ by the modified t-test. Two-way ANOVA for middle panel; $\mathrm{p}=$ 0.00002 (drugs), 0.802 (time points), and 0.099 (interaction). (*), $\mathrm{p}<0.01$ by the modified t-test. Two-way ANOVA for lower panel; $\mathrm{p}=0.442$ (drugs), 0.605 (time points), and 0.186 (interaction).

aortic pressure decreased. These changes, however, were not statistically significant. The preloads of both the right and left ventricles were higher in Group 1 than those in Group 2 at the beginning of drug-treatment (Fig. 2). Such over-loading of the ventricles was gradually corrected after CPZ treatment (Fig. 2).

As shown in Fig. 3, the cardiac output in Group 1 gradually increased despite the decrease in the preloads (Fig. 2), while systemic vascular resistance decreased (Fig. 3). By contrast, in the ST-treated group (Group 2), the cardiac output tended to decrease while the systemic vascular resistance increased (Fig. 3). Meanwhile, left cardiac work did not change significantly in either of the groups during this period, although that of Group 1 appeared to gradually increase.

\section{Case}

A 19-year-old woman with infective endocarditis due to Streptococcus sanguis and resulting acute mitral regurgitation was admitted to our department in September 1988 because of increasing left heart failure and emacia- 
tion (height $160 \mathrm{~cm}$, weight $36 \mathrm{~kg}$ ). Although her endocarditis seemed to be almost controlled (CRP, $\max 5.4 \mathrm{mg} / \mathrm{dl} \rightarrow 0.5 \mathrm{mg} / \mathrm{dl}$; WBC, $\max 15880 /$ $\mathrm{mm}^{3} \rightarrow 6990 / \mathrm{mm}^{3}$ ) by the appropriate antibiotic therapy with 18 million units/day of benzylpenicillin for 20 days, she was still in New York Heart Association functional class IV after continuous intravenous administration of $5 \mu \mathrm{g} / \mathrm{kg} / \mathrm{min}$ of dobutamine for 12 days. During surgery, the anterior and posterior leaflets of the mitral valve showed edematous changes. The posterior chordae of the anterior leaflet were torn. Mitral valve replacement with a $27 \mathrm{~mm}$ St. Jude Medical valve was performed under aortic cross clamping for $65 \mathrm{~min}$ and cardiopulmonary bypass for $110 \mathrm{~min}$. After weaning from the cardiopulmonary bypass with $8 \mu \mathrm{g} / \mathrm{kg} / \mathrm{min}$ of dobutamine plus $6 \mu \mathrm{g} / \mathrm{kg} / \mathrm{min}$ of dopamine, the cardiac index decreased from $2.60 \mathrm{l} / \mathrm{min} /$ $\mathrm{m}^{2}$ at the end of cardiopulmonary bypass to $1.351 / \mathrm{min} / \mathrm{m}^{2}$ in 1 hour. IABP, therefore, was employed in the operating room.

In the ICU, severe LOS continued (Fig. 4). The systemic vascular resistance was gradually increased despite the use of $0.6 \mu \mathrm{g} / \mathrm{kg} / \mathrm{min}$ of SNP and $0.6 \mu \mathrm{g} / \mathrm{kg} / \mathrm{min}$ of NTG. To maintain mean aortic pressure of $>70$ $\mathrm{mmHg}, 18-20 \mathrm{mmHg}$ of left atrial pressure and central venous pressure in addition to $8 \mu \mathrm{g} / \mathrm{kg} / \mathrm{min}$ of dopamine plus $10 \mu \mathrm{g} / \mathrm{kg} / \mathrm{min}$ of dobutamine were required. An oral catecholamine, denopamine (Kalgut; Tanabe, Osaka), at a dose rate of $10 \mathrm{mg} / 8 \mathrm{hr}$ was administered via the nasogastric tube. Urine output was $1-2 \mathrm{ml} / \mathrm{kg} / \mathrm{hr}$ under the extensive use (305 $\mathrm{mg}$ in the first $14 \mathrm{hr}$ ) of furosemide. Blood gas data including base excess were within normal

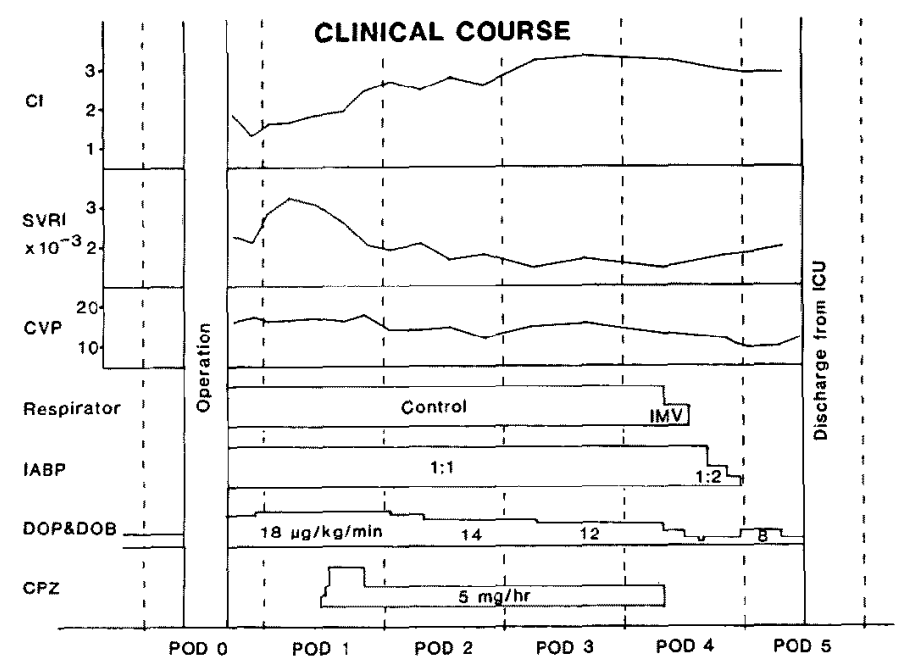

Fig. 4. Representative clinical course in a patient given constant intravenous chlorpromazine. See text for details. 
limits under respirator conditions of $\mathrm{FIO}_{2} 0.3$ and a ventilatory volume of $6 \mathrm{l} / \mathrm{min}$.

In the early morning of postoperative day (POD) 1, the patient awoke, and was quite nervous, anxious, and restless. The patient communicated frequently with the nurse on duty by exchanging written notes, during which monitoring signals of ECG and radial arterial pressure tended to be noisy. Therefore, $2.5 \mathrm{mg} / \mathrm{hr}(0.07 \mathrm{mg} / \mathrm{kg} / \mathrm{hr})$ of CPZ was started and was increased up to $10 \mathrm{mg} / \mathrm{hr}(0.28 \mathrm{mg} / \mathrm{kg} / \mathrm{hr})$ after an hour, while SNP was reduced and discontinued after 6 hours in order to maintain a constant systemic mean arterial pressure of $>70 \mathrm{mmHg}$. The patient slept well and was awakened only during the suctioning of sputa.

After CPZ infusion was started, the systemic vascular resistance decreased and the cardiac output increased markedly. The left atrial and central venous pressures also decreased over time. CPZ was continued for approximately 3 days. First the respirator and then the IABP were removed on POD 4 (Fig. 4). The patient was discharged from the ICU on POD 5.

\section{Discussion}

Vasodilator therapy is commonly administered after cardiac operations, especially for patients with left ventricular failure. ${ }^{\text {1)-9) }}$ Vasodilators reduce afterload while optimizing preload. Reduction in systemic vascular resistance leads to lower wall tension, resulting in less left ventricular work (lower myocardial oxygen requirements) and a more favorable myocardial $\mathrm{O}_{2}$ balance. The same end result occurs through decreasing the preload.9) As long as adequate filling pressures are maintained, the maximal benefit of this therapy is obtained. ${ }^{8,9)}$ In this sense, continuous intravenous CPZ provided an excellent effect on the ill heart supported by IABP plus catecholamines in the present study. Stinson et al ${ }^{7}$ reported that CPZ decreased systemic vascular resistance and increased cardiac output. As an untoward effect, CPZ increased heart rate by $20 \%$ over the pretreatment value. ${ }^{7}$ In their study, however, CPZ was given by repeated bolus injections of $2.5 \mathrm{mg}$ intravenously (average total dose $10.3 \mathrm{mg}$ ). In the present study, no significant change in systemic arterial pressure or heart rate was observed, although we used an average dose of $190 \mathrm{mg} /$ day (range; 59-370 mg). This difference is probably attributable to the different injection methods. In our method, moreover, another vasodilator, SNP, was replaced with CPZ when SNP was used before CPZ. Taken together, these facts suggest that CPZ can be safely and beneficially used as a vasodilator by infusing it intravenously in a constant fashion instead of administering it in a bolus injection. 
The production of sedation and the reduced control over hemodynamics compared with SNP or NTG may be major causes for the less frequent use of CPZ than in the past for its vasodilating effect.9" In the IABP patients, however, the production of sedation was considered to be perfectly suitable, because it enabled their life lines, including the triggers of IABP, to be well secured so that the IABP functioned steadily. Moreover, this drug did not affect the cough reflex. Thus, the suctioning of sputa was not impaired. The decreased control of hemodynamics could be minimized by infusing the drug continuously in a small starting dose. In severe LOS patients, the support with IABP and catecholamines tends to be prolonged as presented in the present study (Table II). Therefore, concomitant vasodilator therapy is also necessary for a prolonged period. In such situations, CPZ appeared to cause much less tolerance than SNP or NTG.

The constant intravenous barbiturate, ST, was also deemed effective in sedating the patients with IABP. This drug, however, has a negative inotropic action, and increases the peripheral vascular resistance, ${ }^{15)}$ although these changes were not statistically significant in the present study (Fig. 3). Barbiturates are usually used for patients with acute brain insults, in order to extend rudimentary neurological functions during severe hypoxia, limit the area of infarction following cerebral vascular occlusion, and reduce intracranial pressure. ${ }^{16}$ ) After cardiac surgery, these drugs are considered to be beneficial for patients with air embolism during cardiopulmonary bypass. 101,11) As predicted from the main effect (suppression of metabolism) on the brain, ST may be negatively inotropic to the heart by suppressing its metabolism, which is suggested by the marginal decrease in left cardiac work (Fig. 3). It is difficult to draw a conclusion as to the ultimate superiority of the 2 drugs, CPZ or ST, in reducing patient mortality. However, $\mathrm{CPZ}$ was clearly superior to ST, at least in improving the hemodynamics of patients with severe LOS.

Although the maximum parenteral dose of CPZ for Japanese adults has been indicated to be $400 \mathrm{mg} /$ day $^{17}{ }^{17}$ this drug is considered to be remarkably safe and adult patients have survived doses of CPZ of up to $10 \mathrm{~g}^{18)}$ In the present study, no severe untoward effects of CPZ such as refractory hypotension, extrapyramidal effects, and agranulocytosis, were observed. In order not to exceed the maximum dose of (CPZ), in this study we utilized doses of less than $370 \mathrm{mg} /$ day. In some patients, however, CPZ $>300 \mathrm{mg} /$ day was not always sufficient to keep them constantly asleep. In such patients we added other sedatives such as diazepam or fentanyl administered in a bolus injection, especially at night. Further increments in the dose of $\mathrm{CPZ}$ may prove to be possible for these patients. 


\section{Acknowledgments}

We would like to thank Associate Professor Brian T. Quinn at the Institute of Languages and Cultures, Kyushu University for his assistance with the English edition of the manuscript. The authors are grateful to $\mathrm{K}$. Inayoshi for her expert secretarial assistance.

\section{REFERENGES}

1. Kantrowitz A, Tjonneland S, Freed PS, Phillips SJ, Butner AN, Sherman JL Jr: Initial clinical experience with intraaortic balloon pumping in cardiogenic shock. JAMA 203: 113, 1968

2. Laird LD, Madras PN, Jones RT, et al: Theoretical and experimental analysis of the intraaortic balloon pump. Trans Am Soc Artif Int Organs 14: 338, 1968

3. Smith LW, Dimsdale JE: Postcardiotomy delirium: Conclusions after 25 years? Am J Psychiatry 146: 452, 1989

4. McIntosh TK, Bush HL, Yeston NS, et al: Beta-endorphin, cortisol and postoperative delirium: A preliminary report. Psychoneuroendocrinology 10: 303, 1985

5. Naber D, Bullinger M: Neuroendocrine and psychological variables relating to post-operative psychosis after open-heart surgery. Psychoneuroendocrinology 10: 315, 1985

6. Aitkenhead AR: Intravenous anesthetic agents. in Textbook of Anesthesia, 1st Ed, ed by Aitkenhead AR, Smith G, Churchill Livingstone, New York, p 175-91, 1990

7. Stinson EB, Holloway EL, Derby $G$, et al: Comparative hemodynamic responses to chlorpromazine, nitroprusside, nitroglycerin, and trimethaphan immediately after open-heart operations. Circulation 51-52 (suppl I): 26, 1975

8. Stinson EB, Holloway EL, Derby G, et al: Control of myocardial performance early after open-heart operations by vasodilator treatment. J Thorac Cardiovasc Surg 73: 523, 1977

9. Fyman PN, Cottrell JE, Kushins I., Casthely PA: Vasodilator therapy in the perioperative period. Can Anaesth Soc J 33: 629, 1986

10. Mills NL, Ochsner JL: Massive air embolism during cardiopulmonary bypass: Causes, prevention, and management. J Thorac Cardiovasc Surg 80: 708, 1980

11. Diethrich EB, Koopot R, Maze A, Dyess N: Successful reversal of brain damage from iatrogenic air embolism. Surg Gynecol Obstet 154: 572, 1982

12. Sari A, Matayoshi $Y$, Yonei A, et al: Cerebral arteriovenous oxygen content difference during barbiturate therapy in patients with acute brain damage. Anesth Analg 65: 1196, 1986

13. Wallenstein S, Zucker CL, Fleiss JL: Some statistical methods useful in circulation research. Circ Res 47: 1, 1980

14. Glantz SA: Biostatistics: How to detect, correct and prcvent errors in the medical literature. Circulation $61: 1,1980$

15. Harvey SC: Hypnotics and sedatives. in Goodman and Gilman's The Pharmacological Basis of Therapeutics, 6th Ed, ed by Gilman AG, Goodman LS, Gilman A, MacMillan, New York, p 339-75, 1980

16. Shapiro HM: Barbiturates in brain ischemia. Br J Anaesth 57: 82, 1985

17. Drugs in Japan; ethical drugs, 9th Ed, Yakugyo Jiho, Tokyo, p 305-6, 1985

18. Baldessarini RJ: Drugs and the treatment of psychiatric disorders. in Goodman and Gilman's The Pharmacological Basis of Therapeutics, 6th Ed, ed by Gilman AG, Goodman LS, Gilman A, MacMillan, New York, p 391-447, 1980 